\title{
PEMBERIAN NON-NUTRITIVE SUCKING (PACIFIER) TERHADAP RESPON NYERI NEONATUS YANG DILAKUKAN PEMASANGAN INFUS
}

\author{
Theresia Anita Pramesti ${ }^{1}$, I Gusti Ayu Ratna Padmasari ${ }^{2}$, Zainal Firdaus Wardhana ${ }^{3}$ \\ 1.Sekolah Tinggi Ilmu Kesehatan Wira Medika PPNI Bali \\ 2.Rumah Sakit Prima Medika Denpasar \\ 3.Institut Ilmu Kesehatan Medika Persada Bali \\ Email: loly.frutcy@gmail.com
}

\begin{abstract}
Abstrak
Nyeri pada neonatus dapat mengakibatkan perilaku fisiologi dan respon metabolik yang negatif. Paparan nyeri dapat merusak perkembangan otak bayi dan menimbulkan gangguan belajar serta perilaku di masa anak-anak. Penelitian ini bertujuan untuk mengetahui pengaruh non nutritive sucking (pacifier) terhadap respon nyeri neonatus yang dilakukan pemasangan infus. Desain penelitian menggunakan static group comparation pada 20 sampel yang diambil dengan consecutive sampling. Pengumpulan data menggunakan lembar observasi. Hasil penelitian menunjukkan rata-rata respon nyeri pada kelompok perlakuan 6,20 dan pada kelompok kontrol 11,40. Hasil Independent t-test didapatkan hasil $p=0,00<\alpha$ $(\alpha=0,05)$ yang berarti ada pengaruh pemberian non nutritive sucking (pacifier) terhadap respon nyeri neonatus yang dilakukan pemasangan infus. Nyeri saat pemasangan infus dialihkan dengan efek analgetik non nutritive sucking yang mengaktifkan jalur opioid oleh stimulasi mekanisme orotactile dan mechanoreceptor sehingga nyeri teralihkan. Non nutritive sucking (pacifier) dapat menjadi salah satu alternatif nonfarmakologi dalam meminimalisasi nyeri pada neonatus.
\end{abstract}

Kata kunci: neonatus, non nutritive sucking (pacifier), nyeri

\begin{abstract}
Applying Non-Nutritive Sucking (Pacifier) To The Neonatus Near Response Infused. Pain in the neonate may result in physiological behavior and negative metabolic responses. Exposure to pain can damage the baby's brain development and lead to learning disorders and behavior in childhood. This study aims to determine the effect of nonnutritive sucking (pacifier) on neonatal pain responses conducted by infusion. The study design use static group comparation in 20 samples taken with consecutive sampling. Data collection use observation sheets. The results showed the average of pain response in the treatment group of 6.20 and in the control group of 11.40. Independent t-test results obtained $p=0.00<\alpha$ $(\alpha=0,05)$ which means there is influence of nonnutritive sucking (pacifier) applying to neonate pain response by infusion. The pain during infusion is diverted with a nonnutritive sucking analgesic effect that activates the opioid pathway by stimulation orotactile and mechanoreceptor so the pain is distracted. Nonnutritive sucking (pacifier) is able to be one of the nonpharmacological alternatives in minimizing pain in neonates.
\end{abstract}

Keywords: neonates, non-nutritive sucking (pacifier), pain. 


\section{Pendahuluan}

Masa neonatus merupakan masa yang sangat rawan karena memerlukan penyesuaian fisiologik agar diluar kandungan dapat hidup dengan sebaikbaiknya. Keadaan yang menyebabkan neonatus harus menjalani hospitalisasi diantaranya karena lahir tidak segera menangis (asfiksia), bayi berat badan lahir rendah (BBLR), air ketuban yang bercampur dengan mekonium serta kelainan bawaan (Badr LK, et al., 2012). Salah satu prosedur invasif yang sering dilakukan pada neonatus yang menjalani hospitalisasi adalah pemasangan infus. Komplikasi yang dapat terjadi dalam pemasangan infus serta pemberian cairan melalui infus adalah rasa perih atau nyeri (Badr LK, et al., 2012).

Neonatus/bayi aterm jika dibandingkan dengan bayi kurang bulan/preterm memiliki karakteristik yang kompleks dalam hal merespon terhadap rangsangan nyeri, dimana bayi aterm lebih ekspresif serta memiliki kemampuan berontak yang lebih kuat dibandingkan dengan bayi preterm/prematur. Keadaan tersebut membuat tenaga kesehatan memiliki kesulitan dalam melakukan tindakan invasif yang berujung terjadinya penusukan berulang. Tingginya angka kesakitan dan kematian neonatus merupakan sebuah fenomena yang bermakna, diperkirakan 2/3 kematian dibawah usia 1 tahun terjadi pada 28 hari pertama. Data di seluruh dunia 2,6 juta bayi lahir meninggal pada tahun 2009 (UNICEF, 2012). Pada tahun 2010 dari 7200 kematian bayi 98\% di antaranya terjadi di negara berpenghasilan rendah dan menengah sedangkan $2 \%$ terjadi di negara yang berpenghasilan tinggi, seperempat sampai setengahnya terjadi dalam 24 jam pertama kelahiran dan disebabkan lahir terlalu dini dan kecil, infeksi, sesak napas (WHO, 2013). Angka kesakitan anak di Indonesia berdasarkan Survei Kesehatan Nasional (Susenas) tahun 2012 di daerah perkotaan menurut kelompok usia 0-4 tahun sebesar 25,8\%, usia 5-12 tahun sebanyak 14,91\%, usia 13-15 tahun sekitar 9,1\%, usia 16-21 tahun sebesar $8,13 \%$. Belum sempurnanya sistem organ neonatus saat dilahirkan mengakibatkan neonatus membutuhan pengobatan dan perawatan yang intensif agar dapat bertahan dan melanjutkan kehidupannya. Neonatus sering terpapar dengan prosedur tindakan invasif yang dapat menyebabkan nyeri selama masa perawatan, salah satunya adalah pemasangan infus (vena line). Sulitnya 
pemasangan infus pada neonatus oleh karena ukuran vena yang masih kecil dan terbatasnya perawat profesional dalam hal pemasangan infus pada bayi menyebabkan seringnya terjadi penusukan berulang kali. Belum ada angka yang pasti tentang prevalensi kegagalan pemasangan infus pada neonatus di Indonesia. Ini disebabkan karena penelitian yang berkaitan dengan terapi intravena dan publikasinya masih jarang (Widayati, et al., 2016). Melihat tingginya angka kesakitan neonatus diperlukan adanya kemajuan di bidang pelayanan kesehatan untuk meningkatkan prospek dan daya tahan hidup bayi terutama yang sangat kurang bulan melalui perawatan intensive.

Dampak nyeri pada neonates dapat bersifat jangka pendek dan jangka panjang. Pemecahan cadangan lemak dan karbohidrat, peningkatan morbiditas merupakan dampak jangka pendek sedangkan jangka panjangnya berupa penolakan terhadap kontak manusia, keterlambatan perkembangan, gangguan neurobehavioral, gangguan belajar, kinerja motorik buruk, defisit perhatian, tingkah laku adaptif buruk, ketidakmampuan mengahadapi situasi baru, peningkatan respon stres hormonal dikehidupan dewasa kelak (Wong, 2008). Terdapat dua metode umum untuk terapi nyeri yaitu farmakologik dan non farmakologik (Kyle \& Carman, 2014). Upaya non farmakologik yang digunakan untuk mengurangi nyeri diruang intensive bayi diantaranya pemberian non nutritive sucking (NNS), yaitu dengan memberikan dot dari silikon (empeng) ke mulut bayi untuk merangsang penghisapan tanpa pemberian ASI ataupun susu formula. Bagi neonatus mulut merupakan instrumen primer untuk menerima rangsang dan kenikmatan, oleh karenanya intervensi untuk meminimalisir nyeri dilakukan sesuai kebutuhan guna memperkuat perkembangan fisik, psikososial, dan neurologis yang optimal. Sherwood (2009) menjelaskan bahwa nyeri merupakan mekanisme proteksi untuk menimbulkan kesadaran akan kenyataan bahwa sedang atau akan terjadi kerusakan jaringan. Persepsi nyeri berada pada area kortek (fungsi evaluatif kognitif) yang muncul akibat stimulus menuju saraf spinotalamikus dan talamiko kortikalis.

Pemasangan infus dilakukan untuk memenuhi kebutuhan nutrisi atau obat melalui jalur parentral serta mempertahankan keseimbangan cairan dan elektrolit. Prosedur yang diterapkan di rumah sakit mewajibkan perawat 
melakukan tindakan penusukan untuk pemasangan infus maksimal sebanyak 2 kali tusukan. Apabila melakukan penusukan lebih dari 2 kali perawat diwajibkan membuat kronologis penyebab kegagalan. Data yang diperoleh dari bulan Oktober 2016 sampai bulan Desember 2016 ditemukan 9 kasus kegagalan dalam pemasangan infus. Salah satu penyebab kegagalan karena bayi yang terus menangis dan meronta saat dipasang infus. Dari latar belakang tersebutlah peneliti ingin melakukan penelitian mengenai pengaruh pemberian nonnutritive sucking (pacifier) terhadap respon nyeri pada neonatus yang dilakukan pemasangan infus.

\section{Metode}

Jenis penelitian yang digunakan peneliti pada penelitian ini yaitu pra eksperiment. Desain yang digunakan adalah static group comparation. Rancangan ini merupakan rancangan pra eksperimental dengan menambah kelompok kontrol. Tempat penelitian ini adalah RS Prima Medika Denpasar. Penelitian ini dilaksanakan pada tanggal 15 Mei -15 Juni 2017. Populasi yang digunakan dalam penelitian ini adalah neonatus yang dirawat di ruang NICU RS Prima Medika Denpasar yang dilakukan pemasangan infus sebanyak 42 neonatus. Jumlah sampel yang digunakan dalam penelitian ini yaitu 20 responden yang dipilih menggunakan teknik non probability sampling jenis Consecutive sampling.

Penelitian ini menggunakan dua variabel yaitu variabel bebas dan variabel terikat. Variabel bebas dalam penelitian ini adalah pemberian non nutritive sucking (pacifier) sedangkan variabel terikatnya yaitu respon nyeri neonatus yang dipasang infus. Instrumen pengumpulan data yang digunakan yaitu PIPP (Premature Infant Pain Profile) terdiri dari indikator: usia gestasi, tahapan perilaku, laju jantung, saturasi, kerutan dahi, mata tertutup rapat, lipatan nasolabial mendalam. Rentang skor 0-21, setelah dijumlahkan maka skor minimum adalah 0 dan skor maksimum adalah 21. Internal consistency menggunakan alpha cronbach 0,75-0,59, standarisasi system alpha untuk 6 item 0,71 .

Teknik analisa data yang digunakan dalam penelitian ini adalah analisa univariat dan bivariat. Analisis univariat digunakan untuk menggambarkan distribusi frekuensi karakteristik responden Pada penelitian ini variabel univariat yaitu karakteristik responden yang terdiri dari usia gestasi, 
tahapan perilaku, laju jantung, saturasi oksigen, mata tertutup rapat, kerutan dahi dan lipatan nasolabial mendalam. Distribusi frekuensi variabel terikat respon nyeri neonatus, nilai mean, standard deviasi, nilai maksimum, dan minimum. berdasarkan uji shapiro-wilk didapatkan hasil bahwa data berdistribusi normal, sehingga pengolahan data menggunakan uji Independent t-test.

\section{Hasil}

Hasil penelitian dipaparkan dalam bentuk tabel yang menyajikan data karakteristik responden, variable penelitian, dan analisa data.

\section{Tabel 1 Karakteristik Responden} Berdasarkan Usia Gestasi

\begin{tabular}{lccc}
\hline Kelompok & $\mathrm{N}$ & $\begin{array}{c}\text { Mean } \\
\text { (Dalam minggu) }\end{array}$ & $\mathrm{SD}$ \\
\hline Perlakuan & 10 & 37.70 & 0.823 \\
Kontrol & 10 & 37,80 & 1,033 \\
\hline
\end{tabular}

Pada tabel 1 dapat dilihat karakteristik responden berdasarkan usia gestasi pada kelompok perlakuan dan kelompok kontrol memiliki usia aterm atau cukup bulan yaitu 37-40 minggu

\section{Tabel 2 Karakteristik Responden} Berdasarkan Tahapan Perilaku

\begin{tabular}{lccccc}
\hline Kelompok & $\mathrm{N}$ & Mean & $\mathrm{SD}$ & $\max$ & $\min$ \\
& & & & & \\
\hline Perlakuan & 10 & 1,60 & 0,843 & 3 & 0 \\
Kontrol & 10 & 2,60 & 0,516 & 3 & 2 \\
\hline
\end{tabular}

Berdasarkan tabel 2 karakteristik responden berdasarkan tahapan perilaku pada kelompok perlakuan nilai minimall yang diperoleh yaitu 0 yang artinya neonatus menunjukkan perilaku tenang/tertidur, mata tertutup, dan tidak ada gerakan wajah saat pemasangan infus. Nilai minimum kelompok kontrol adalah 2 yaitu aktif/terbangun, mata tertutup, ada gerakan wajah.

\section{Tabel 3 Karakteristik Responden} Berdasarkan Kerutan Dahi

\begin{tabular}{cccccc}
\hline Kelompok & $\mathrm{N}$ & Mean & SD & $\max$ & $\min$ \\
\hline Perlakuan & 10 & 0,70 & 0,483 & 1 & 0 \\
Kontrol & 10 & 1,70 & 0,483 & 2 & 1 \\
\hline
\end{tabular}

Berdasarkan tabel 3 karaktristik responden berdasarkan kerutan dahi pada kelompok perlakuan nilai maksimum adalah 1 yang berarti neonatus menunjukkan kerutan dahi minimal, pada kelompok kontrol didapatkan nilai maksimal adalah 2 yang berarti kerutan dahi sedang

Tabel 4 Karakteristik Responden Berdasarkan Saturasi Oksigen

\begin{tabular}{cccccc}
\hline Kelompok & $\mathrm{N}$ & $\begin{array}{c}\text { Mean } \\
(\%)\end{array}$ & SD & Max & Min \\
\hline Perlakuan & 10 & 89,50 & 4,950 & 97 & 82 \\
Kontrol & 10 & 83,10 & 5,896 & 90 & 74 \\
\hline
\end{tabular}

Berdasarkan respon nyeri neonatus berdasarkan saturasi oksigen didapatkan nilai maksimum pada 
Pramesti, T.A, I Gusti Ayu Ratna Padmasari, I.G.A \& Wardhana, Z.A, Pemberian Non-Nutritive Sucking (Pacifier) Terhadap Respon Nyeri Neonatus Yang Dilakukan Pemasangan Infus

kelompok perlakuan adalah $97 \%$ dan

nilai maksimum pada kelompok kontrol adalah $90 \%$

Tabel 5 Karakteristik Responden Berdasarkan Laju Jantung

\begin{tabular}{cccccc}
\hline Kelompok & $\mathrm{N}$ & $\begin{array}{c}\text { Mean } \\
(\mathrm{x} / \mathrm{mnt})\end{array}$ & $\mathrm{SD}$ & Max & Min \\
\hline Kontrol & 10 & 148,40 & 10,189 & 160 & 130 \\
Perlakuan & 10 & 135,70 & 7,243 & 149 & 125 \\
\hline
\end{tabular}

Berdasarkan tabel 5 karakteristik responden berdasarkan laju jantung maximum pada kelompok kontrol adalah $160 \mathrm{x} /$ menit dan pada kelompok perlakuan nilai maximum adalah 149 $\mathrm{x} / \mathrm{menit}$

Tabel 6 Karakteristik Responden Berdasarkan Mata Tertutup Rapat

\begin{tabular}{cccccc}
\hline Kelompok & $\mathrm{N}$ & Mean & SD & Max & Min \\
\hline Kontrol & 10 & 1,70 & 0,675 & 3 & 1 \\
Perlakuan & 10 & 1,00 & 0,471 & 2 & 0 \\
\hline
\end{tabular}

Berdasarkan tabel 6 karakteristik responden berdasarkan mata tertutup rapat pada kelompok kontrol memiliki nilai maximum 3 yang artinya mata tertutup maksimal nilai maksimum pada kelompok perlakuan adalah 2 yang berarti mata tertutup sedang

\section{Tabel 7 Karakteristik $\quad$ Responden Berdasarkan Lipatan Nasolabial Mendalam}

\begin{tabular}{cccccc}
\hline Kelompok & $\mathrm{N}$ & Mean & SD & Max & Min \\
\hline Kontrol & 10 & 1,50 & 0,527 & 2 & 1 \\
Perlakuan & 10 & 0,70 & 0,483 & 1 & 0 \\
\hline
\end{tabular}

Berdasarkan tabel 7 karakteristik responden berdasarkan lipatan nasolabial mendalam pada kelompok perlakuan memiliki nilai maximum 1 yang artinya lipatan nasolabial mendalam minimal dan pada kelompok kontrol nilai maximum 2 yang berarti lipatan nasolabial mendalam sedang.

Tabel 8 Gambaran Nyeri Pada Kelompok Perlakuan

\begin{tabular}{cccccc}
\hline Kelompok & $\mathrm{N}$ & Mean & SD & Max & Min \\
\hline Perlakuan & 10 & 6,20 & 1,3978 & 9 & 4 \\
\hline
\end{tabular}

Berdasarkan tabel 8, gambaran nyeri neonatus pada kelompok perlakuan memiliki nilai maximum 9 yaitu kategori nyeri sedang.

Tabel 9 Gambaran Nyeri Pada Kelompok Kontrol

\begin{tabular}{cccccc}
\hline Kelompok & $\mathrm{N}$ & Mean & SD & Max & Min \\
\hline Kontrol & 10 & 11,40 & 1,35 & 13 & 9
\end{tabular}

Berdasarkan karakteristik responden berdasarkan gambaran nyeri neonatus pada kelompok kontrol memiliki nilai maximum 13 yaitu nyeri berat.

Tabel 10 Analisis Perbedaan Respon Nyeri Yang Dilakukan Pemasangan Infus Pada Kelompok Kontrol Dan Perlakuan

\begin{tabular}{ccccc}
\hline Kelompok & $\mathrm{N}$ & Mean & $\mathrm{SD}$ & $\begin{array}{c}\text { Independent } \\
\text { t test }\end{array}$ \\
\hline Perlakuan & 10 & 6.20 & 1,398 & \\
Kontrol & 10 & 11,40 & 1.35 & $\mathrm{P}=0,000$ \\
\hline
\end{tabular}


Berdasarkan tabel 10 hasil uji independent t-test didapatkan nilai $p$ value $0,000(\mathrm{p}<\alpha)$ sehingga dapat disimpulkan ada pengaruh pemberian non nutritive sucking (pacifier) terhadap respon nyeri neonatus saat dilakukan pemasangan infus.

\section{Pembahasan}

\section{Gambaran Nyeri Responden Pada Kelompok Kontrol}

Tabel 7 menunjukkan bahwa gambaran nyeri pada kelompok kontrol dengan rata-rata $11,40 \pm 1,3$, rentang nyeri pada kelompok kontrol nilai tertinggi yaitu 13 dan nilai terendah 9 . Hockenberry (2009) mengklasifikasikan nyeri dimana nilai nyeri 0 menunjukkan tidak nyeri, 1-6 menunjukkan nyeri minimal/ringan, nilai antara 7-12 menunjukkan nyeri sedang dan nilai lebih dari 12 menunjukkan nyeri hebat. Nilai tertinggi untuk bayi kurang bulan yaitu 21 dan untuk cukup bulan yaitu 18. Komponen afektif nyeri adalah emosi yang tidak menyenangkan berhubungan dengan sensasi yang dinamakan distres nyeri, kecemasan dan ketidaknyamanan (Wong, 2008)

Pada tabel 1 berdasarkan usia gestasi neonatus pada kelompok kontrol memiliki rata-rata $37,80 \pm 1,033$, semua responden dalam kelompok kontrol memiliki usia gestasi aterm/cukup bulan. Devi (2012) menyatakan dimana usia gestasi sangat berpengaruh terhadap respon nyeri, nyeri pada neonatus ditunjukkan melalui ekspresi, gerakan badan dan status fisiologis. Menurut Wong (2008), karena perkembangan bahasa neonatus yang sangat terbatas maka pengalaman nyeri neonatus dapat dinilai melalui perubahan perilaku seperti ekspresi wajah, gerak tubuh, menangis dan istirahat, neonatus memiliki luas permukaan tubuh yang lebih besar dari dewasa sehingga kepadatan nosiseptor nyeri lebih besar dan sekresi endorphine kurang sehingga neonatus lebih rentan terhadap nyeri.

$$
\text { Kyle \& Carman (2014) }
$$
menyatakan bayi baru lahir yang dirawat di NICU yang terpapar oleh teknologi tinggi terkait dengan prosedur-prosedur untuk menyelamatkan kehidupan, umumnya akan mengalami sensitifitas yang tinggi terhadap kerusakan jaringan dan terjadi penurunan ambang nyeri. Hal ini berhubungan dengan respon biobehavioral terhadap rasa nyeri. Menurut Kyle \& Carman (2014) menjelaskan neonatus yang mengalami prosedur yang menyakitkan selama perawatan akan meningkatkan tingkat 
stres yang dapat diukur melalui kortikol saliva dan lebih stabil secara fisiologis, dapat dilihat dari penurunan rata-rata denyut jantung dan stsbilitas saturasi O2. Laju jantung pada kelompok kontrol mengalami peningkatan yang signifikan dari sebelum dilakukan pemasangan infus Tabel 5 menunjukkan laju jantung maksimal pada kelompok kontrol adalah $160 \mathrm{x} /$ menit (tinggi) dan nilai rata-rata 148,40 , dan berdasarkan tabel 4 saturasi oksigen maksimal pada kelompok kontrol adalah 90 dan nilai minimum 74 dengan nilai rata-rata 83,10 . Pada kelompok kontrol terjadi penurunan saturasi oksigen yang signifikan. Penurunan saturasi oksigen terjadi $5-10 \%$ dari saturasi awal (sebelum pemasangan infus). Pada kelompok kontrol juga terjadi penusukan lebih dari satu kali, hal ini dapat mengakibatkan meningkatnya angka kesakitan atau morbiditas pada neonatus. Potter (2010) menyatakan kerusakan dan iskemia jaringan akan menyebabkan pelepasan lokal dari prostaglandin, serotonin, bradikinin, norepineprin, dan substansi pain. Substsnsi ini menstimulasi respon dari nociceptor perifer terhadap stimulus nyeri. Hasil akhir dari sensasi nyeri ini adalah respon sistemik berupa fight and flight. Hormon terhadap stres akan dilepaskan termasuk epineprin, norepineprin, glucagon, cortisol, aldosteron, thyroid stimulating hormon (TSH), dan hormon peertumbuhan. Hormon-hormon ini akan mempengaruhi berbagai sistem di tubuh yang bermanifestasi pada peningkatan denyut jantung, tekanan darah, curah jantung, gangguan motilitas saluran cerna, serta gangguan sistem imun, semua faktor ini akan menyebabkan gangguan penyembuhan dan meningkatkan faktor infeksi, akhirnya morbiditas dan lama perawatan akan bertambah.

Nyeri pada bayi yang tidak segera diobati dan berlangsung dalam waktu lama dapat berpengaruh pada perilaku pada saat dewasa nantinya. Kusumaningsih (2016) menjelaskan dalam penelitiannya nyeri pada neonatus dapat mengakibatkan perilaku fisiologis dan respon metabolik yang negatif. Beberapa tanda dan gejala nyeri pada bayi/neonates antara lain menangis lebih keras, lebih tinggi melengking dan dapat berlangsung lebih lama dari biasanya dan terjadinya perubahan tanda-tanda vital seperti peningkatan detak jantung, tingkat pernafasan, jumlah oksigen dalam darah, serta perubahan ekspresi wajah bayi dan perilaku. Perubahan fisiologis yang 
ekstrim bisa menjadi faktor yang berpengaruh terhadap kejadian hipoksia, hiperkarbi, yang berakibat dapat merusak perkembangan otak bayi dan berkontribusi terhadap gangguan belajar dan perilaku di masa kanak-kanak.

Gambaran Nyeri Responden Pada Kelompok Kontrol

Berdasarkan tabel 6 rerata nyeri neonatus saat dilakukan pemasangan infus pada kelompok perlakuan adalah $6,20 \pm 1,398$. Berdasarkan hasil ratarata respon nyeri yang diperoleh pada kelompok perlakuan, rata-rata responden mengalami nyeri ringan. Neonatus yang menggunakan non nutrititive sucking memiliki respon nyeri ringan sampai sedang. Dari data yang diperoleh dapat dilihat pada tabel 8 skor tertinggi respon nyeri neonatus pada kelompok perlakuan adalah 9 (nyeri sedang) dan skor terendah pada kelompok perlakuan adalah 4 (nyeri ringan). Non nutritive sucking adalah salah satu strategi untuk mengurangi respon nyeri pada neonatus, pernyataan ini sesuai dengan pendapat Kyle \& Carman (2014) yang menyatakan upaya nonfarmakologi yang digunakan untuk mengurangi nyeri salah satunya non nutritive sucking yang merupakan instrumen untuk meminimalisasi nyeri. Semakin tinggi skor maka semakin nyeri. Non nutritive sucking mempunyai efek analgetik non farmakologis sebagai intervensi pereda rasa sakit. Reflek hisap yang terjadi mengakibatkan stimulasi sensoris yang mengurangi tanggapan neonatus terhadap nyeri.

Kozier (2010) menyatakan pada neonatus, tipe nosiseptor perifer telah sama dengan dewasa sehingga desentis nosiseptor neonatus persatuan luas kulit lebih tinggi dibandingkan dewaasa. Mielinisasi yang belum sempurna baik pada saraf A delta dan $\mathrm{C}$ perifer maupun saraf spinalis diteruskan ke korda spinalis yang dapat menyebabkan spasme otot sehingga timbul withdrawal reflex. Sensitisasi sentral dapat terjadi pada korda spinalis. Stimulasi reseptor N-Methyl D-Aspartate (NMDA) akan meningkatkan eksitabilitas neuron di sekitarnya (wind-up phenomena). Hal ini menyebabkan bayi mengalami penurunan ambang nyeri (hiperalgesia) dan peningkatan respon nyeri jaringan sekitar (alodynia). Hasil penelitian ini didukung oleh penelitian Devi (2012) yang menyatakan penggunaan kombinasi pemberian non nutritive sucking dan sukrosa terhadap respon nyeri neonatus setelah dilakukan pemasangan infus, didapatkan $\mathrm{p}=0,000$ yang menunjukkan bahwa terdapat perbedaan respon nyeri yang signifikan 
pada bayi setelah pemasangan infus antara kelompok intervensi dan kelompok kontrol. Arwismasari (2015) yang meneliti aplikasi tindakan pemberian kombinasi non nutritive sucking dan sukrosa terhadap respon nyeri pemasangan infus didapatkan hasil pada 7 dari 10 responden pada kelompok kontrol yang tidak diberikan non nutritive sucking dan glukosa didapatkan skala nyeri berat, sedangkan pada kelompok intervensi didapatkan 5 dari 10 responden memiliki skala nyeri sedang.

Pemberian non nutritive sucking (pacifier) saat pemasangan infus memiliki skala nyeri ringan sampai sedang. Faktor yang mempengaruhi nyeri salah satunya usia gestasi dan usia neonatus. Pada tabel 1 rata-rata usia gestasi pada kelompok perlakuan adalah 37,70 dimana usia gestasi juga mempengaruhi respon neonatus terhadap nyeri, semakin matur gestasi neonatus semakin jelas pula respon nyeri yang ditampilkan. Non nutritive sucking (pacifier) selain berfungsi memberikan kenyamanan selama menjalani prosedur medis juga membantu bayi agar lebih cepat untuk tidur dibuktikan dengan laju jantung yang relatif stabil saat dilakukan pemasangan infus. Hal ini dapat dilihat pada tabel 5 rata-rata laju jantung pada kelompok perlakuan adalah 135,70 dan nilai maksimum untuk laju jantung 149 (sedang). Pada tabel 3 rata-rata terjadinya penusukan berulang pada kelompok perlakuan adalah 1,30 penusukan lebih dari sekali disebabkan oleh beberapa faktor, saat penelitian berlangsung terdapat faktor penyulit sehingga tidak dapat dilakukan penusukan hanya sekali. Salah satunya dikarenakan tenaga kesehatan yang melakukan pemasangan infus memiliki keahlian dan jam terbang yang tidak sama. Selain itu pemasangan infus tidak hanya dilakukan di radiant warmer tetapi juga dilakukan di incubator. Tempat untuk dilakukannya pemasangan infus juga mempengaruhi respon nyeri, hal ini disebabkan karena posisi yang kurang nyaman akan menyebabkan neonatus untuk menangis sehingga mengaburkan hasil penelitian apakah bayi menangis karena posisi yang tidak nyaman atau karena nyeri penusukan infus.

\section{Analisis Perbedaan Respon Nyeri} Pada Kelompok Perlakuan Dengan Kelompok Yang Kontrol

Berdasarkan tabel 8 hasil analisis respon nyeri kelompok perlakuan lebih rendah dibandingkan dengan kelompok kontrol, ini dapat dibuktikan dengan 
Pramesti, T.A, I Gusti Ayu Ratna Padmasari, I.G.A \& Wardhana, Z.A, Pemberian Non-Nutritive Sucking (Pacifier) Terhadap Respon Nyeri Neonatus Yang Dilakukan Pemasangan Infus

nilai rerata kelompok kontrol lebih tinggi yaitu 11,40 dibandingkan kelompok perlakuan dengan nilai rerata 6,20. Hasil analisis statistik menggunakan uji independent $t$ test didapatkan $\mathrm{p}=0,000$ dimana $\mathrm{p}<0,005$ menunjukkan terdapat perbedaan respon nyeri pada kelompok kontrol dengan kelompok perlakuan. Hal tersebut juga menunjukkan bahwa ada pengaruh pemberian non nutritive sucking terhadap respon nyeri neonatus yang dilakukan pemasangan infus. Berdasarkan respon hart rate (HR) maksimal saat pemasangan infus pada kelompok perlakuan menunjukkan nilai rata-rata 135,70 dan pada kelompok kontrol 148,40 sedangkan untuk respon saturasi oksigen menunjukkan nilai ratarata pada kelompok perlakuan 89,50 dan pada kelompok kontrol 83,10 yang berarti ada perbedaan respon HR dan saturasi oksigen yang signifikan saat pemasangan infus dengan menggunakan non nutritive sucking. Hal ini sesuai dengan pernyataan Lubis (2006) dalam Devi (2012) bahwa perubahan fisiologis yang menunjukkan respon nyeri pada bayi ditunjukkan dengan perubahan warna kulit, telapak tangan berkeringat, stres dan peningkatan frekuensi jantung, tekanan darah, respirasi, dan tekanan intra kranial. Pernyataan ini juga diperkuat oleh penelitian yang dilakukan Arwismasari (2015) yang menyatakan kombinasi penggunaan sukrosa dan non nutritive sucking dapat menurunkan skala nyeri saat dilakukan pemasangan infus dapat dilihat dari respon nyeri pada kelompok perlakuan yang memiliki nilai lebih rendah dari kelompok kontrol. Lowyer (2014) dalam Arwismasari (2015) menyatakan bahwa kombinasi pemberian non nutritive sucking dan sukrosa dapat memberikan sifat seperti analgesik.

Pada kelompok perlakuan lebih sedikit dilakukan penusukan berulang hal ini disebabkan karena bayi lebih tenang saat pemasangan infus, pernyataan ini sesuai dengan pendapat Devi (2012) non nutritive sucking (pacifier) bekerja dengan cara mengeluarkan opioid endogen yang berada di saraf decenden. Teori pengalihan perhatian menurut Melzack Wall (1965) dalam Kosim (2007) menyatakan bahwa impuls nyeri dapat diatur atau dihambat oleh mekanisme pertahanan di sepanjang sistem saraf pusat.

Teori ini menyatakan bahwa impuls nyeri dihantarkan saat sebuah pertahanan dibuka dan impuls dihambat saat sebuah pertahanan tertutup. Upaya penutupan pertahanan tersebut 
merupakan dasar teori menghilangkan nyeri. Mekanoreseptor, neuron beta-A yang lebih tebal, yang lebih cepat melepaskan neurotransmiter penghambat. Apabila masukan yang dominan berasal dari serabut beta-A, maka akan menutup mekanisme pertahanan. Diyakini pemberian pacifier merupakan mekanisme penutupan. Alur saraf desenden melepaskan opiat endogen, seperti endofin dan dinorfin, suatu pembunuh nyeri alami yang berasal dari tubuh (Perry dan Potter, 2008).

Hasil penelitian ini sesuai dengan penelitian yang dilakukan oleh Kristinawati (2013) dalam penelitiannya yang berjudul pemberian sukrosa dan non nutritive sucking terhadap respon nyeri dan lama tangis neonatus pada prosedur invasif, didapatkan perbedaan yang signifikan, pada kelompok perlakuan (yang diberikan sukrosa 24\%) respon nyerinya lebih rendah dan lama tangisnya lebih singkat dibandingkan kelompok kontrol. Hasil yang diperoleh dari penelitian Kristiawati P value 0,635 $(\mathrm{p}<0,05)$ dimana sukrosa oral $24 \%$ efektif dalam menurunkan respon nyeri dan lama tangis pada neonatus yang dilakukan tindakan invasif.

Perbedaan respon nyeri dan skala nyeri neonatus pada kelompok perlakuan dan kelompok kontrol tidak hanya dipengaruhi oleh usia gestasi dan usia neonatus tetapi juga dipengaruhi oleh cara perawat melakukan stuing saat pemasangan infus dan jumlah penusukan yang dilakukan. Berdasarkan hasil penelitian yang telah dilakukan didapatkan bahwa non nutritive sucking (pacifier) efektif untuk meminimalisasi nyeri dibuktikan dengan respon nyeri dari kelompok perlakuan antara ringan sampai sedang. Berdasarkan pengamatan peneliti pada kelompok perlakuan tidak semuanya dilakukan penusukan berulang, hanya ada 2 responden yang dilakukan penusukan lebih dari sekali. Nyeri yang dirasakan neonatus pun berbeda antara neonatus yang hanya dilakukan penusukan hanya sekali dengan yang dilakukan penusukan lebih dari sekali. Hal tersebut menjadi suatu tantangan bagi tenaga kesehatan khususnya perawat di ruang NICU agar lebih memperhatikan respon nyeri pada neonatus untuk meminimalkan angka kesakitan dan angka morbiditas

\section{Kesimpulan}

Rata-rata gambaran nyeri neonatus saat dilakukan pemasangan infus pada kelompok perlakuan adalah 6,20 dengan standar deviasi 1,398 . Nilai 
tertinggi skor nyeri neonatus pada kelompok perlakuan adalah 9 (nyeri sedang) dan skor nyeri terendah adalah 4 (nyeri ringan). Rata-rata gambaran nyeri pada kelompok kontrol dengan rerata 11,40 dengan standar deviasi 1,35 , rentang nyeri pada kelompok kontrol nilai tertinggi yaitu skor 13 (nyeri berat) dan nilai terendah skor 9 (nyeri sedang). Hasil analisis respon nyeri kelompok perlakuan lebih rendah dibandingkan dengan kelompok kontrol, ini dapat dibuktikan dengan nilai rerata kelompok kontrol lebih tinggi dibandingkan kelompok perlakuan. Berdasarkan uji statistic independent $t$ test didapatkan nilai $\mathrm{p}$ values $=0,000(\mathrm{p}$ $<0,005)$ dimana H0 ditolak dan Ha diterima yang berarti ada pengaruh pemberian non nutritive sucking (pacifier) terhadap respon nyeri neonatus yang dilakukan pemasangan infus

\section{Referensi}

Arwismasari, A. (2015). Aplikasi Tindakan Pemberian Kombinasi Non Nutritive Sucking dan Sukrosa Terhadap Respon Nyeri pemasangan infus pada Asuhan Keperawatan By. A Dengan Berat Badan Lahir Rendah (BBLR). Diperoleh dari http://www.digilib.stikeskusumah usada.ac.id

Astuti, D. D., Yeni Rustina \& Fajar Tri Waluyanti. (2016). "Empeng" Efektif Menurunkan Nyeri Bayi saat Pengambilan Darah Vena. Jurnal Keperawatan Indonesia, 19(2).

Badr, L.K., Abdallah, B., Hawari, M., Saadieh, S., Kassar, M., Nakad, P., \& Breidi, J. (2010). Determinants of premature infant pain responsses to heel sticks. Pediatric Nursing, 36 (3), 129136. Diperoleh dari https://www.ncbi.nlm.nih.gov/pub med/20687304

Devi, S. K., (2012). Efektivitas Pemberian Kombinasi Non Nutritive Sucking (NNS) dan Sukrosa TerhadapRespon Nyeri Neonatus Setelah Dilakukan Tindakan Pemasangan Infus. Diperoleh dari https://www.lib.ui.ac.id

Dewi, R. S., (2014). Efektifitas Sukrosa Oral Terhadap Respon Neri Akut Pada Neonatus yang Dilakukan Tindakan Pemasangan Infus. Diperoleh dari http://www.ejurnal.com/2016/11/efektifitassukrosa-oral-terhadap.html

Hockenberry, M. \& Wilson, D., (2009). Wong Essentials of Pediatric Nursing. 8 th ed. St.Louis: Elsevier.

Kosim, M. S. et al., (2007). Buku Ajar Neonatologi. Jakarta: Sagung Seto.

Kozier, B. S., (2010). Buku Ajar Foundamental Keperawatan Konsep, Proses \& Praktik. 7 ed. Jakarta: EGC.

Kusumaningsih, F. S., (2016). Pemberian Air Susu Ibu Pada Neonatus Untuk Mengurangi Nyeri Akibat Pengambilan Sampel Darah. Diperoleh dari Jurnal Keperawatan, JanuariApril, 1(Coping Ners), pp. 9-17.

Kyle, T. \& Carman, S., (2014). Buku Ajar Keperawatan Pediatri. vol. 2 ed. Jakarta: t.p. 
M. Rudolph, A., I. E. Hoffman, J. \& D. Rudolph, C., (2006). Buku Ayat Pediatri. volume I ed. 20 ed. Jakarta, E6C: s.n.

Potter, P. A. \& Perry, A. G., (2010). Fundamental Keperawatan. 7 ed. Jakarta: Salemba Medika.

Potter \& Perry, (2006). Fundamental Keperawatan. 7 ed. Jakarta: Salemba Medika.

Sherwood, L., (2009). Fisiologi Manusia dari Sel ke Sistem. 8 ed. Jakarta: EGC.

Susenas. (2012). Profil Kesehatan Indonesia. Diperoleh dari https://www.depkes.go.id

Tarwoto, W. d., (2006). Kebutuhan Dasar manusia Dan Proses Keperawatan. 3 ed. Jakarta: Salemba Medika.

UNICEF, (2012). Penurunan angka kematian ibu dan anak. [Online] Diperoleh dari https://www.unicef.org

Widayati, K., D.P.,Putu Yuli Kurniati \& G.A Trisna Windiani, (2016). Faktor Risiko Sepsis Neonatorum di Ruang Perinatologi Rumah Sakit Umum Sanglah Denpasar, 1(1), pp. 85-92. (Laporan hasil penelitian tidak dipublikasikan).

Wong, D. L., (2008). Keperawatan Pediatrik. 6 ed. St. Louis: Mosby Elseiver. 